\title{
소방특별사법경찰제도의 효율적인 운영방안에 관한 연구 A Study on the Effective Operation Method of Special Judicial Police System For Fire Service
}

\author{
정현균* · 황의홍** · 최돈묵*** \\ Jeong, HyunKyun*, Hwang, Euyhong**, and Choi, Donmook ${ }^{* * *}$
}

\begin{abstract}
According to the analysis of the National Emergency Management Agency's statistics in 2017, there have been 528 cases of interference in firefighting activities over the past three years, and has been increasing every year. However, since the fire department has not been able to efficiently operate a task force that can detect and transmit fire activities, it is not actively responding by relying on the police to arrest the suspect even if there is an obstruction of fire. Based on the statistics of the fire department, this study analyzed the operation standards and limitations of the fire department in Gyeonggi Province, which ranks first in the number of fires, rescues, and rescue operations in the whole country, and presented problems and solutions for them.
\end{abstract}

Key words : Fire Crime, Special Judicial Police for Fire Service, Investigative Team

\section{요 지}

2017년 소방청 통계를 분석해보면 최근 3년간 소방활동 방해사범은 528건으로 해마다 증가 추세에 있다. 그러나 일선 소방서는 현재 소방활동 방해사범을 적발하고 송치할 수 있는 수사 전담팀을 효율적으로 운영하지 못하고 있어 소방활동 방해사건이 발생하여도 현행범인으로 체포하는 과정을 경찰에 의존하는 등 적극적인 대응이 이루어지지 못하고 있는 것이 현실이다. 본 연구에서는 소방청 통계를 바탕으로 전국에서 화재·구조·구급 출동건수 1 위 지역인 경기도 소방관서의 소방특별사법경찰 의 운영기준과 한계를 분석하고, 이에 대한 문제점과 해결방안을 제시하였다.

핵심용어 : 소방활동 방해사범, 소방특별사법경찰, 수사전담팀

\section{1. 연구 배경 및 목적}

최근 막대한 인명 및 재산 피해를 초래한 대형화재 사건들 이 꾸준히 발생하고 있다. 대형화재가 되는 원인으로 초기소 화의 실패, 소방관 출동시간 지연, 구조 및 구급 골든타임 초과 등이 있다.

초기소화의 실패의 원인은 소방차의 화재현장 진입의 실패, 화재인지의 지연 등이 있다. 소방시설을 제대로 관리하 지 않고 매뉴얼대로 조작하지 않으면 재실자의 대피까지도
영향을 준다.

소방차 출동시간 지연은 불법 주- 정차, 출동방해, 소방차 주차구역 미확보 등에서 나타난다.

Table 1은 최근 3년간 경기도에서 소방법 위반현황으로 사법처리 실적은 총 1,000 건이다. 소방활동 방해사범을 제외 한 실적으로 위반사례는 더 많이 존재한다.

구조 및 구급 골든타임 초과는 인명피해와 직접적인 관계 가 있다고 할 수 있다. Table 2는 최근 3년간 경기도의 구급대 원에 대한 소방활동 방해사범에 대한 처리현황을 분석한

*정회원, 가천대학교 산업환경대학원 산업환경공학과 석사(E-mail: naraku@gg.go.kr)

Member, Master, Fire Protection Engineering, Gachon University

**정회원, 가천대학교 설비소방공학과 석사과정

Member, Master Candidate, Fire Protection Engineering, Gachon University

***교신저자, 정회원, 가천대학교 설비소방공학과 교수(Tel: +82-31-759-5716, Fax: +82-31-759-8749, E-mail: fire@gachon.ac.kr)

Corresponding Author, Member, Professor, Fire \& Disater Protection Engineering, Gachon University 
Table 1. Fire-fighting Law Violators Current Status of Judicial Processing (Gyeonggi Fire and Disaster Headquarters, 2017)

\begin{tabular}{c|c|c|c|c|c}
\hline \multirow{2}{*}{ Years } & Total & $\begin{array}{c}\text { Framework Act on } \\
\text { Fire Services }\end{array}$ & $\begin{array}{c}\text { Fire-fighting } \\
\text { Facilities }\end{array}$ & $\begin{array}{c}\text { Fire-Fighting } \\
\text { System Installation } \\
\text { Business Act }\end{array}$ & $\begin{array}{c}\text { Safety Control of } \\
\text { Dangerous } \\
\text { Substances Act }\end{array}$ \\
\hline Total & 1,000 & 58 & 388 & 98 & 456 \\
\hline 2016 & 355 & 19 & 126 & 54 & 156 \\
\hline 2015 & 300 & 20 & 129 & 23 & 128 \\
\hline 2014 & 345 & 19 & 133 & 21 & 172 \\
\hline
\end{tabular}

Table 2. Disturbance from Fire Field Activity Current Status of Judicial Processing (Gyeonggi Fire and Disaster Headquarters, 2017)

\begin{tabular}{|c|c|c|c|c|c|c|c|c|c|c|}
\hline \multirow{3}{*}{ Years } & \multicolumn{10}{|c|}{ Contents } \\
\hline & \multicolumn{3}{|c|}{ Investigation Main Agent } & \multicolumn{7}{|c|}{ Convicts' Punishment Results } \\
\hline & Total & $\begin{array}{c}\text { Fire } \\
\text { Fighting }\end{array}$ & Police & Total & Jail & Penalty & $\begin{array}{c}\text { Delay } \\
\text { Indictment }\end{array}$ & $\begin{array}{l}\text { Suspended } \\
\text { Sentence }\end{array}$ & Trial & Etc. \\
\hline Total & 528 & 221 & 307 & 528 & 127 & 220 & 32 & 3 & 91 & 55 \\
\hline 2016 & 199 & 94 & 105 & 199 & 42 & 44 & 11 & - & 82 & 20 \\
\hline 2015 & 198 & 72 & 126 & 198 & 62 & 96 & 9 & 1 & 9 & 21 \\
\hline 2014 & 131 & 55 & 76 & 131 & 23 & 80 & 12 & 2 & - & 14 \\
\hline
\end{tabular}

것이다. 사건들은 매년 증가하고 있는 추세이며 구급대원 폭행에 대한 국민들의 법 감정에 비해 전체 528 건의 폭행사 건중 구속인원은 38 건에 불과해 $7.2 \%$ 의 낮은 구속율을 보였 다. 생명이 위급한 사람에게 응급 구조 활동을 수행하는 구급대원에게 폭력과 폭언을 행사하는 행위에 대해서는 엄정한 법 집행이 필요하다.

소방특별사법경찰은(이하 “소방특사경”이라 한다.) 화재 사건에서 관계인 등의 법령위법 여부를 판단하고 소방대원 이 출동 및 진압, 구조 및 구급활동 방해범죄를 적발하여 검찰에 송치할 수 있다.

본 연구는 표본 신뢰도 확보를 위해 화재 - 구조 - 구급 출동건수 및 소방범죄 발생율· 송치율 전국 1 위인 경기도 소방관서를 대상으로 하였으며 소방특사경의 효율적 운영 을 위한 직무영역과 관계법령을 살펴보고, 내부적으로는 소방특사경 업무의 타 부서로의 이전, 수사인력 부족, 업무의 특성이 고려되지 아니한 인사행정으로 인한 수사관들의 전문성 결여 등의 여건에 대한 개선 방안을 제시하고자 한다.

\section{2. 소방특별사법경찰에 대한 고찰}

\section{1 소방관계법령의 정의}

소방관계법령(이하 “소방관계법령”이라 한다.)이란소방 기본법, 화재예방, 소방시설 설치 - 유지 및 안전 관리에 관한 법률, 소방시설공사업법, 위험물안전관리법, 다중이용업소 의 안전관리에 관한 특별법, 119 구조- 구급에 관한 법률,
초고층 및 지하연계 복합건축물 재난관리에 관한 특별법의 총 7개 법령을 말한다.

\section{2 소방사범}

\subsection{1 소방사범의 정의}

소방사범이란 소방관계법령에서 규정하는 의무를 불이 행함으로서 범죄가 성립하는 경우를 말하며, 법령을 위반한 관계인(소유자, 점유자, 관리자)을 말한다.

위반의 죄책은 징역 또는 벌금형을 부과하고 있어 넓은 의미로 형법의 범주에 포함되어 형법총칙의 적용을 받는다. 또한 범죄예방 효과의 실효성 확보를 위해 위반행위자와 그 법인 또는 개인에게 벌금형을 과하는 양벌규정을 두고 있다(Chae and Woo, 2009).

\subsection{2 소방사범의 특성}

소방사범의 특성은 상습성, 관계인의 무관심, 기술적 이해 필요로 구분하였으며 내용은 다음과 같다.

\subsubsection{1 상습성}

소방사범은 형법상의 범죄행위에 비해 범죄 기법과 형태 가 비교적 단조로운 반면 그 위법행위가 지속적인 형태로 발생하는 상습적 특징이 있다.

예를 들어 위반 대상물 관계인의 소방안전시설의 설치와 유지 - 관리, 위험물 저장 - 취급의 안전관리, 소방시설업자 의 법령준수 등 관련 범죄유형이 비교적 단순하고 변화가 
거의 없으며 새로운 유형의 범죄발생 가능성이 적다. 생활에 필요한 물건이거나, 당장 불편한 요소가 아니어서 위반한 상태를 인식하지 못한 상태로 위반행위가 그대로 유지되는 상습성이 있다(Chae and Woo, 2009).

\subsubsection{2 관계인의 무관심}

건물의 신축과 함께 설치된 소방시설은 시간이 흐름에 따라 누수현상이나 소방펌프의 고장, 감지기 등에 문제가 지속적이며 꾸준하게 발생하게 된다. 정기적인 점검과 유지 관리비를 불필요 비용으로 생각하고, 작위 또는 부작위가 범죄라는 생각은 인식하지 못하거나, 관계인의 무관심 등으로 인해 소방사범으로 단속되고 있는 실정이다.

예를 들어 2018년 8월 인천의 남동구의 한 공장에서 실제 로 화재가 발생하였으나, 평소 오동작으로 경보설비가 작동 하여, 당연히 오동작으로 인식하고 안이한 대처로 많은 사상 자가 발생한 사례가 있다.

\subsubsection{3 기술적 이해 필요}

소방관계법령은 규제적 법률로 대상물의 관계인에 대해 설치된 소방시설의 유지 - 관리 의무를 부여하고 있으나 건물주 등 관계인의 인식부족과 현실적인 문제로 자격증만 보유한 고령의 인력 채용으로 선제적 예방차원의 점검이 불가능하게 되고 결국 유사시 인명피해와 재산의 큰 손실로 이어지는 악순환이 반복되고 있다.

\subsection{3 소방사범의 유형}

소방사범의 유형은 소방활동 방해사범, 명령(작위 의무) 위반사범, 인 - 허가업무 위반사범, 기타 관계법령 위반사범 으로 구분하였으며 내용은 아래와 같다.

\subsubsection{1 소방활동 방해사범}

「소방기본법」 제 16 조에 ‘정당한 사유없이 출동한 소방대 의 화재진압 및 인명구조 - 구급 등 소방활동을 방해하면 안 된다'라고 규정되어 있는 사항을 위반하고 위력을 사용, 현장 출동 또는 출입을 고의로 방해, 출동한 소방대원에게 폭행 또는 협박 행위, 출동한 소방대의 소방장비를 파손 또는 효용을 해하는 행위이다.

\subsubsection{2 명령(작위 의무) 위반사범}

소방시설 불량에 대한 시정보완명령, 화재 등 위급 상황에 서의 대피명령, 무허가 장소의 위험물에 대한 조치명령에 따르지 않는 행위이다.

\subsubsection{3 인 - 허가 업무 위반사범}

임의로 제조소 등을 설치 또는 변경시 대상물의 관계자 및 공사업자가 설치 또는 변경허가를 득하지 않고 지속적으 로 사용하는 행위이다.
또한, 관계인 또는 공사업자들이 관행처럼 행해지는 선 시공 위반, 배관매립 등의 위반 행위도 이에 속한다.

\subsubsection{4 기타 관계법령 위반사범}

일정 면적 이상의 건축물 신축, 소방시설 공사현장, 위험물 을 저장, 취급, 제조하는 시설 등에서는 반드시 안전관리자 나, 공사감리자, 감리원을 선임하거나 배치 또는 지정해야할 의무가 있음에도 간과하는 경우가 많이 있다.

\section{3 소방특별사법경찰제도}

\subsection{1 소방특별사법경찰제도의 정의}

사회의 발전에 따라 법령이 기능, 업무, 소관부처, 물질, 특별법 등 세분화 및 다양화 되면서 전문성이 떨어지는 일반경찰은 위반사항에 대한 단속 등 직무 수행이 어려워 졌다(Gyeonggi Fire and Disaster Headquarters, 2017).

소방특별사법경찰(이하 “소방특사경 제도”라 한다.) 제도 란 관할 구역에서 발생하는 소방사범들에 대해 관계법령 및 업무의 전문성을 갖춘 소방공무원에게 사법권을 부여하 여 수사의 효율성을 높여 수사의 목적을 달성하기 위해 개정된 제도이다.

\subsection{2 소방특별사법경찰의 업무의 범위}

소방특사경은 소방관계법령과 사법경찰관리의 직무를 수행할 자와 그 직무범위에 관한 법률에 근거하여 소방활동 방해, 소방공무원 폭행 및 화재현장에서 소방관계법령 위반 사범에 대해 수사 및 송치 업무를 수행하고 있다.

\section{3. 소방특별사법 경찰의 현실태}

\section{1 인원현황}

Table 3은 경기도내 소방특사경 인원 현황으로 계급별 현황은 특별사법경찰 총 411 명중 사법경찰관 282명(68\%), 사법경찰리 129 명 $(31 \%)$ 이 지명되어있다. 사법경찰리가 실 제 소방특사경 업무를 전담, 수행하고 있어 인원이 부족한 실정이다.

\section{2 교육현황}

Table 4는 2014년부터 2016년까지 3년간 경기도 소방특사 경 지명자의 수사관련 교육 이수 인원은 총442명으로 법무연 수원 153 명, 경기도소방학교 289명이다.

\section{3 전문성}

경력현황은 2 년 이하 경력자는 320 명(78\%), 2년 이상 경력자는 91 명 $(22 \%)$ 으로 나타났다. 이는 평균 1년 1.5년 마다 잦은 조직개편에 따른 인사요인과 위반사범을 상대하 고 벌칙을 부과해야 하는 업무와 타 업무를 함께 하는 
Table 3. Personnel Status (Gyeonggi Fire and Disaster Headquarters, 2017)

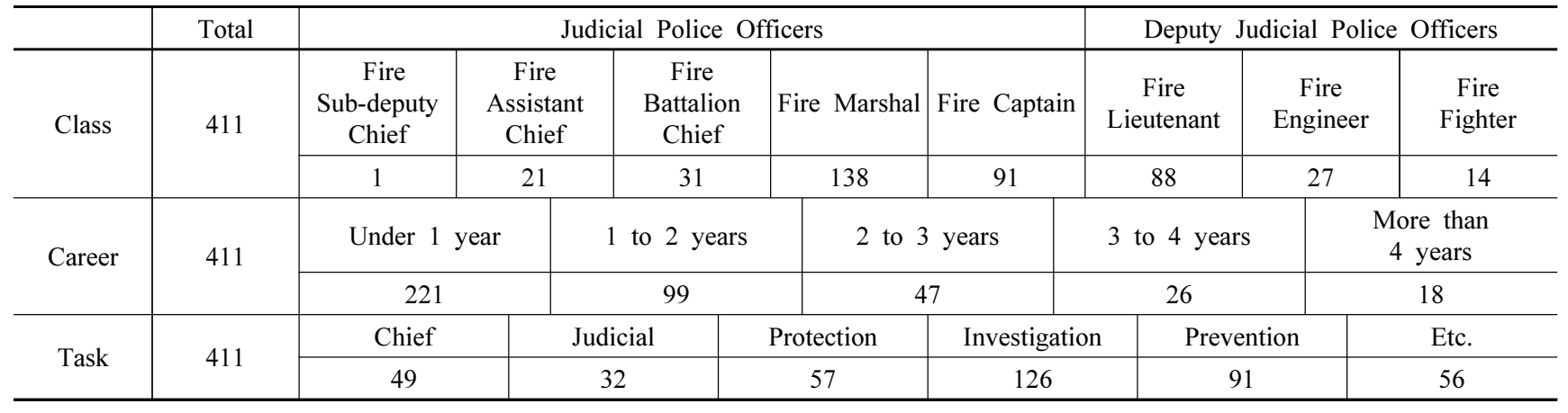

Table 4. Education Status (Gyeonggi Fire and Disaster Headquarters, 2017)

\begin{tabular}{c|c|c|c}
\hline Contents & Total & Legal Training Institute & fire school \\
\hline Total & 442 & 153 & 289 \\
\hline 2016 & 249 & 87 & 162 \\
\hline 2015 & 83 & 15 & 68 \\
\hline 2014 & 110 & 51 & 59 \\
\hline
\end{tabular}

부담감과 가중으로 당해 업무를 기피 하는 요인으로 나타나 고 있다.

업무별 현황은 소방서별 실질적인 특사경 업무 전담자는 32 명 $(8 \%)$ 이고, 그 외 대다수가 화재조사 및 예방업무 등을 병행하고 있으며 화재조사관의 경우 화재현장에서 소방시 설 차단 및 정상작동 여부, 무허가 위험물 등 단속업무를 겸하고 있다. 화재 신고와 동시에 출동하여 조사를 실시하기 때문에 신속한 증거 확보가 가능한 장점이 있으나, 화재조사 관의 업무를 병행하는 관계로 피의자 수사 및 송치업무는 수행하지 않는다.

\section{4. 소방특별사법경찰의 문제점}

\section{1 인력부족}

현재 소방관서별 소방특사경 업무 담당자는 1 명으로 사법 업무에만 전념할 수 있는 여건을 갖춘 소방서는 단 1 곳도 없는 것이 현실이다. 2016년 경기도 사법처리 실적 및 과태료 부과 현황은 347건, 2,097건으로 전국에서 압도적인 1위로 업무하중이 타 시도에 비해 월등하게 높다.

또한 소방서 재난예방과 전체의 업무량에 비해 부족한 인원으로 소방특사경 업무 담당자에게도 타 업무가 2 3개 분야의 업무를 수행하고 있다. 예를 들면 소방관서별로 사무 분장이 상이하지만, 민원부서에 근무하는 관계로 다중이용 업소 완비증명 및 방염처리 업무, 소방안전관리자 및 위험물 안전관리자 선 - 해임 신고 업무 등을 처리하게 된다.

\section{2 교육미흡}

2014년부터 2016년까지 소방특사경 직무교육 이수 현황
을 보면 경기도 소방특사경 지명자는 411명이며, 3년간 교육 이수인원은 442 명으로 $(108 \%)$, 비율을 보면 법무연수원이 152 명(34.6\%), 소방학교가 289명(65.4\%)으로 연1회 이상의 교육을 이수하였으나, 형사소송절차 4시간, 수사실무1(범죄 인지, 참고인 조사) 3 시간, 수사실무2(피의자신문, 체포·구 속) 4시간, 수사실무3(압수수색 - 검증, 통신수사) 3시간, 수 사실무4(수사결과보고, 의견서 작성, 송치서) 4 시간, 신문기 법, 법정증언기법 3 시간, 수사실무 실습 8시간, 소방관련 판례해설 2 시간, 과태료 체납처분 2 시간의 1 주교육(총 33 시 간)으로 소방활동 방해사범, 구급대원 폭행사범 체포 등 다양한 범죄수사 업무에 바로 적용하기에는 실무적으로 어려움이 따른다.

\section{3 전문성부족과 수사업무의 한계}

34 개 소방서의 소방특사경 중 업무와는 전혀 관계없는 다른 사무를 동시에 수행하는 경우가 대부분으로 수사능력 향상을 위한 시간을 따로 마련하기 어려운 실정이다. 경기도 소방관서 조직 개편에서도 사법업무 담당부서가 타 부서로 이동하며, 담당직원 또한 타 부서의 직원으로 변경되어 업무 의 전문성 향상을 기대하기 어려운 여건이다.

또한 업무적으로 일반사법경찰의 범죄 수법에 비해 단순 하다고 할 수 있으나 소방특사경의 경우에도 7개 법령위반사 범에 대해 현행범인으로 체포하는 과정에서부터 검찰에 송치하는 과정까지의 업무처리 경험이 부족한 대부분의 소방특사경들은 원할한 수사업무를 하기에 한계가 있다.

\section{4 법령 모호성}

소방관계법령에서 규정하고 있는 죄책들 중 일부가 모호 
한 부분이 있다. 「소방기본법」제 16 조 제 2 항 소방활동 방해 죄에 해당하는 법령에서는 "누구든지 정당한 사유 없이 출동한 소방대의 화재진압 및 인명구조· 구급 등 소방활동 을 방해하여서는 아니 된다.”라고 규정되어 있으나 벌칙조항 에서는 모호한 내용이 있다. "출동한 소방대의 소방장비를 파손하거나 그 효용을 해하여 화재진압·인명구조 또는 구급활동을 방해하는 행위”라고 규정되어 있어 사법부와 해석이 양론화 된다. 파손은 '깨어져 못 쓰게되거나' 또는 '깨뜨려 못 쓰게 함'이다(Ministry of Government Legislation, 2018)의 의미를 갖지만, 가령 구급차량만을 발로 걷어차 찌그러트린 경우, 이를 소방활동 방해죄를 적용하여 송치할 수 있을지 의문이다.

\section{5. 소방특별사법경찰의 개선방안}

\section{1 전담팀·전담부서 신설}

전담팀 - 전담부서 신설 및 구성, 수사업무의 연속성단절, 장기근무가 불가능한 인사 시스템, 인원부족에 따른 업무의 다중성으로 업무전문성 결여, 업무기피 현상 등 여러 가지 문제점들을 해소하기 위해서는 먼저 모든 소방관서 재난예 방과에 소방특사경 전담팀을 신설해야 한다. 필요 인원은 102 명으로 기존 인원인 직원 1명(특사경) 34 명을 제외하고 68 명(34개 소방서별 팀장1명, 직원1)의 인원이 더 선발되어 야 한다. 증가하고 있는 구급대원 폭행사건에 적극 대응하고 소방특별조사 및 화재 등 각종 재난현장에서 관계인의 소방 시설 유지관리 상태와 적정 작동 상황 등 단속업무를 수행할 수 있도록 적극 검토되어야 한다.

전담팀 - 전담부서가 신설되면 특사경 팀장 포함 3인으로 구성하며, 수사업무 담당자의 필수 보직 기간을 3 년 이상으 로 제한하여 전담팀 구성원들이 조직 개편으로 인한 수사 업무의 연속성 단절을 막고, 인원부족에 따른 업무의 다중성 을 해소하기 위해 담당사무는 관할 구역 내에서 발생하는 소방관계법령에 대한 위반사범 사법조치 및 과태료로 제한 하며 전문성을 확보하고 그로인한 업무 기피현상을 해소할 수 있다.

\section{2 전문교육 확대}

전문성 강화를 위해서는 강사의 일방적 주입교육이 아닌 상호 토론과 소방서별 수사실무 사례의 공유를 통하여, 수사 관 전체의 수사 역량이 평준화 될 수 있도록 하여야 한다. 일선 소방관서에서 처리되는 크고 작은 소방사범들과 복잡 다양한 소방법률 위반 내용에 따라 처벌법규에 대한 상호 의문점을 토론하고 학습하면서 역량을 높여야 한다. 형식적인 1 회성 교육으로는 당면업무를 처리하는데 턱없이 부족하다.

구급대원 폭행사건 등 소방활동 방해 사범의 급증으로 범행현장에 출동하여 현행범인을 체포하게 되는 경우도 발생하고 있다. 그간 소방특사경의 경우 주로 임의출석에
의한 사건만을 처리하다 보니, 현행범인을 체포하는 과정에 는 광장히 취약하다. 사법경찰의 경우처럼 현행범인의 체포 방법, 체포시 작성해야 할 각종서류, 확인사항 등 현실적이고 실무에 즉각적으로 활용 가능한 교육을 실시하여야 한다. 이를 위해 필수 이수과목에 대한 기준을 제시하면 2주교육 (70시간)의 수사관련 교육이 필요하다고 판단된다. 형사사 법절차 및 형법총론 4시간, 현행범인 체포술(미란다 원칙 고지 등) 10 시간, 수사실무(피의자 죄목 변경 등) 5 시간, 수사실무2(압수수색, 검증, 통신수사 등) 10 시간, 피의자 신문 및 조서 작성 실습(소방활동 방해사범 및 위험물관련 법령, 소방기본법위주) 30 시간, 송치서류 작성 5 시간, 과태료 체납처분 6시간)을 제시한다.

이를 위해서 본부 및 소방학교에 교육 프로그램을 신설하 여 수시로 학습할 수 있도록 제도적으로 교육과정과 장치를 마련하여야 한다. 이 경우 검찰, 경찰 그리고 일선에서 실무경 험이 많은 소방특사경을 강사로 활용하여 전문적인 수사실 무 교육이 필요하다. 더불어 현재 활성화 되어 있는 인재개발 원 사이버 교육프로그램도 개설하여 기초부터 실무까지 강의안을 만들어 배포하고 수시로 학습하고 문의할 수 있도 록 하여야 한다.

\section{3 광역 전문팀 운영}

특사경의 직무범위는 소방관계법령 위반사범에 대한 수 사 및 송치 업무를 수행하고 있다, 위험물 법령 등 분야별로 광범위하여 전문성을 겸비한 경력있는 수사관이 필요하다. 그러나 경기도의 경우 특사경 업무를 5년 이상 근무한 인원이 441 명 중 18 명으로 매우 적다. 전담팀, 전담부서의 신설이 어렵다면 특사경 5 년 이상 근무하였으면서 송치실적 30 건 이상인 자로 화재조사관 자격, 소방 또는 위험물관련 자격을 갖춘 수사관을 전문특사경으로 선발하는 것이 필요하다.

일단은 8 명을 선발하여 4 개 거점소방서 권역별로 2 명씩 배치, 근무하며 일선소방서에서 수사업무에 관한 질문, 요청 사항을 지원하고 또는 자문을 통해 사건처리의 도움을 주는 역할을 하도록 해야 한다.선발된 전문특사경에게 적절한 동기부여와 성취감을 주기 위해 가점2점을 인센티브로 부여 하는 기준도 고려해 볼 필요가 있다.

대형화재와 방화, 실화등 사회적 이목이 집중되는 사건에 도 소방특별전문수사관이 참여토록 하여 소방관계법령분야 의 위법사항에 관한 검토와 자문을 통해 수사 역량과 위상이 높아질 것이다.

\section{4 법령의 보완}

소방기본법 제 50 조의 1 항 라목의 내용 중 “출동한 소방대 의 소방장비를 파손하거나 그 효용을 해하여 화재진압·인 명구조 또는 구급활동을 방해하는 행위”의 법적 조문에서 (Ministry of Government Legislation, 2018) 소방장비의 예시 가 없다는 점과, 파손이나 효용을 해하는 정도나 범위, 방식에 
대해서 언급한 것이 없다는 모호한 부분을 “출동한 소방대의 소방차량 등 소방장비를 고의로 고장, 손상, 파손시키거나 그 효용을 해하여 소방활동을 방해하는 행위"로 수정 및 보완하고, 해당하는 장비에 대한 내용을 별표로 표기하는 것도 하나의 방안이라고 판단된다.

이와 같이 위반사범에 대해 엄정한 법을 집행한다면 각종 사건 - 사고현장에서 소방공무원이 적극적으로 활동할 수 있는 여건을 조성될 수 있다고 판단된다.

\section{6. 결 론}

본 연구의 결론은 다음과 같다.

첫째, 일선 소방서별 특사경 전담팀과 부서를 신설하고, 특사경 전보제한 및 수사업무범위를 지정하여 운영하여 특사경의 전문성을 향상시켜야 한다.

둘째, 수사관련 교육이수, 토론 위주의 교육 등 수사관들이 실무에서 바로 활용할 수 있는 교육과 교육을 참여할 기회를 확대하면 실무적인 어려움이 완화 될 것이라 판단된다.

셋째, 광역 전문특별수사팀을 운영하여 수사경험이 적은 수사관에게 사법처리 방향을 제시하면 내부적으로는 수사 업무역량 및 전문성 확보, 외부적으로는 소방특사경의 위상 이 향상될 것이라 판단된다.

넷째, 소방관계법령상의 기준이 모호한 부분을 법령에 적합하고 현실적으로 정비하여 업무에 혼선을 예방하고
기소에 무리가 없도록 해야 한다.

소방특사경의 수사 여건을 개선하면 소방법익을 침해하 는 자에게 엄정하게 법을 집행할 수 있을 것이다. 최종적으로 화재와 재난 - 재해, 그 밖의 위급한 상황으로부터 국민의 소중한 생명 - 신체 및 재산을 보호하는데 그 목적을 이루는 데 도움이 될 것이라 판단된다.

\section{References}

Chae, J., and Woo, S.C. (2009). The study on the improvement plan by investigation case of the fire crimes. Fire Science and Engineering, Vol. 23, No. 6, pp. 142-151.

Gyeonggi Fire and Disaster Headquarters. (2017). Practice of investion of special law for fire-fighting. pp. 1-3

Ministry of Government Legislation. (2018). Framework Act On Fire-Fighting Services.

National Fire Service Academy. (2009). Fire-Fighting Criminal Treatment. p. 105.

\begin{tabular}{l|l}
\hline Received & March 14, 2019 \\
Revised & March 20, 2019 \\
\hline Accepted & May 7, 2019
\end{tabular}

